\title{
Using Neural Networks to Enhance Technical Trading Rule Returns: A Case with KLCI
}

\author{
By Jacinta Chan Phooi M'ng* \\ Azmin Azliza Aziz ${ }^{\dagger}$
}

\begin{abstract}
In this paper, we test the profitability of technical trading rules which are enhanced by the use of neural networks on the Kuala Lumpur Composite Index (KLCI), a proxy of the Malaysian stock market traded in Bursa Malaysia. The profitable returns on KLCI from 2/1/2008 to 31/12/2014 offer a piece of evidence on the ability of technical trading rules using neural networks to outperform the buy-and-hold threshold benchmark. The test results here suggest that it is worthwhile to investigate, design and develop more robust machine learning algorithms, like neural networks enhanced technical indicators that enhance portfolio returns. The conclusion that can be drawn from this research work is that neural network may be used as tools in technical analysis for future price prediction. The findings from this work will interest all market participants, research analysis and fund managers who want to enhance their portfolio returns globally.
\end{abstract}

Keywords: Neural networks, Stock market index, Technical analysis, Time series analysis, Technical trading rules.

\section{Introduction}

Technical analysts test historical data to establish specific rules for buying and selling securities with the objective of maximizing the profit at the minimal risk (Gencay and Stengos 1998). More than $60 \%$ of commodity trading advisors and $40 \%$ of foreign exchange currency traders use technical analysis in making investment decisions at trading firms and investment banks (Allen and Taylor 1990, Fernandez-Perez et al. 2012). Within the area of algorithmic trading, the interest in high frequency trading and online trading algorithm has grown remarkably over recent years (Neely et al. 2009, Masteika and Rutkauskas 2012). Accompanying this interest is the number of studies about technical trading rules (Lukac et al. 1988, Brock et al. 1992, Park and Irwin 2009) and recently, computational trading algorithms that users find useful for timing investment decisions (Gencay 1998, Gencay and Stengos 1998, Fernandez-Rodriquez et al. 2000). The works of Gencay (1998), Gencay and Stengos (1998) and Fernandez-Rodriquez et al. (2000) are amongst the seminal works evaluating the predictability power of technical trading rules using neural networks while successive contributions involving more advanced

\footnotetext{
${ }^{*}$ Senior Lecturer, University of Malaya, Malaysia.

${ }^{\dagger}$ Senior Lecturer, University of Malaya, Malaysia.
} 
techniques include those of Gehrig and Menkhoff (2006) and Fernandez-Perez et al. (2012).

In the works of Brock et al. (1992), the most popular moving average rule is the 1-200 rule, of which the short period is one day and the long period is 200 days. Other common standards include the 1-50, 1-150, 5-200, and 2-200 rules. Gencay (1998) uses a 1-200 moving average and a 1-200 moving average with volume. The evidence produced by these studies shows that technical trading rules can produce abnormal profits (Lukac et al. 1988, Brock et al. 1992, Park and Irwin 2009). Nevertheless, many have also indicated a slow-moving downtrend for this kind of profitability over the recent decades (Olson 2004, Neely et al. 2009). To outperform the stock markets, increasingly complicated trading rules are needed (Lee and Mathur 1996, Olson 2004). Recently, artificial neural networks (ANNs) have been extensively used in time series forecasting (Zhang 2003).

The aim of this paper is to demonstrate that profitable returns for KLCI above the passive threshold buy-and-hold can be earned by the use of artificial neural networks to enhance the ability of technical analysis indicators. To achieve this aim, three trading strategies involving ANNs predicted values for the next period, are tested against the passive benchmark buy-and-hold strategy. The ANNs inputs are the closing prices and the technical analysis indicators used by Yao et al. (1999) like moving averages (MA), Resistance Strength Index (RSI) and Stochastics D\% and K\%. Extending the research of Yao et al. (1999) on KLCI, this study investigates the viability of the ANNs method. Different from the one of Yao et al. (1999), this study uses a base method which compares the predicted output with the current close. The profitable results of these trading strategies are in accordance with recent findings that statistical learning methods have produced better out-of-sample results (Andrada-Felix and Fernandez-Rodriquez 2008).

This paper evaluates the efficacy of three trading strategies. First it compares the predicted output with the current close, then, the current predicted output with its preceding predicted output, and finally the predicted output with the previous close. The passive buy-and-hold strategy serves as the control.

The rest of the paper is organized as follows. The next section presents a brief description of the data. Subsequently, estimation techniques are described and empirical results are discussed. Last, we present the conclusions.

\section{Data Description}

The data series include daily data of the Kuala Lumpur Composite Index (KLCI), collected from January $2^{\text {nd }} 2008$ to December $31^{\text {st }} 2014$, a total of 1,725 observations from Bloomberg. The training period is determined as about $70 \%$ of these observations, from January $2^{\text {nd }} 2008$ to December $31^{\text {st }}$ 2012; the validation period is about $15 \%$ from January $2^{\text {nd }} 2013$ to December $31^{\text {st }} 2013$ and the out-of-sample period is about $15 \%$ from January $2^{\text {nd }} 2014$ to 
December $31^{\text {st }} 2014$. The daily closes of the KLCI are transformed into daily returns as follows:

$$
R_{i}=\ln \left(\frac{c_{\mathrm{t}}}{c_{\mathrm{t}-1}}\right)
$$

where $R_{t}$ is the daily return of the closes of the KLCI while $C_{t}$ and $C_{t-1}$ are the closes at day $t$ and $t-1$ respectively. The summary of the statistics of the returns are shown in Table 1.

Table 1. Summary Statistics of Daily Returns of KLCI

\begin{tabular}{|c|c|c|c|c|c|c|}
\hline Mean & Min & Max & Std. Dev. & Variance & Kurtosis & Skewness \\
\hline 0.0001 & -0.0998 & 0.0406 & 0.0077 & 0.0001 & 18.9303 & -1.4093 \\
\hline
\end{tabular}

Source: Authors' estimations.

Similar to Yao et al. (1999), the simple 5-days moving average ( $\left.\mathrm{MA}_{5}\right), 10$ days moving average $\left(\mathrm{MA}_{10}\right)$, 50-days moving average $\left(\mathrm{MA}_{50}\right)$, Resistance Strength Index (RSI), Momentum (M), and Stochastic $\% \mathrm{~K}$ and $\% \mathrm{D}$ are extracted from Bloomberg.

\section{Estimation Techniques}

The analysis ascertains if one or more of the technical trading rules are superior to the passive buy-and-hold strategy which is commonly used as a benchmark (Fama 1965). Through a combination of technical indicators as inputs for a layered neural network, the two trading strategies using predicted values (Yao et al. 1999) and a base trading strategy are employed to find abnormal returns as a part of market anomalies. The technical indicators are selected as inputs to the neural network to discover the implicit relationship between the technical indicators and future predicted output. The technical indicators used as inputs, besides the actual close $\left(\mathrm{C}_{\mathrm{t}}\right)$ and previous close $\left(\mathrm{C}_{\mathrm{t}-1}\right)$, are a simple 5-days moving average $\left(\mathrm{MA}_{5}\right), 10$-days moving average $\left(\mathrm{MA}_{10}\right)$, 50-days moving average $\left(\mathrm{MA}_{50}\right)$, the Resistance Strength Index (RSI), Momentum (M), and Stochastic $\% \mathrm{~K}$ and \%D. The output is the next predicted close $\hat{C}_{t+1}$. The moving average of $x$-days is the $x$-days average of the most recent closes. The formula for RSI, $\mathrm{M}, \% \mathrm{~K}$ and $\% \mathrm{D}$ are given as follows:

$$
R S I=100-\frac{100}{1+R S}
$$

where, $\quad R S=$ Average Gain/Average Loss,

Average Gain = Sum of Gains over the past 14 periods/14, Average Loss $=$ Sum of Losses over the past 14 periods/14,

$$
M=C C P-O C P
$$


where, $\quad \mathrm{CCP}=$ Current closing price,

OCP $=$ Old closing price for a predetermined period ( 5 days),

$\% K=\frac{(C C P-L 9)}{(H 9-L 9)} \times 100$

where, $\quad$ L9 $=$ The lowest low of the past 9 days,

$\mathrm{H} 9=$ The highest high of the past 9 days,

$\% D=\frac{H 3}{L 3} \times 100$

where, $\quad \mathrm{H} 3=$ The three day sum of $(\mathrm{CCP}-\mathrm{L} 9)$,

L3 $=$ The three day sum of $(\mathrm{H} 9-\mathrm{L} 9)$.

A trading model is considered ideal if it meets the following criteria: i) it should not produce huge losses or exhibit any net large losses in any of the years; ii) the model should work well both in testing stage and in practice, and that it should adjust automatically to shifts in parameters; and iii) it must produce abnormal returns even after accounting for transaction and slippage costs.

Hence, this study adopts a similar testing approach based on the technical trading rules specified by Yao et al. (1999). The estimation is made using the Artificial Neural Networks (ANNs) model.

Inspired by biological systems, Artificial Neural Networks consist of a collection of highly interconnected processing units called neurons or nodes. These neurons are organized in layers, specifically in an input layer, one or more hidden layers and an output layer. Each neuron is associated with a weight that represents the strength of a connection between two neurons in the network. The weight values are determined by an iterative flow of learning processes. Backpropagation is one of the commonly used training procedures that fall in a class of feedforward networks, where the information is passed from the input layer towards the output layer through the hidden layer(s). The advantages of ANNs include its robustness, its ability to approximate nonlinear functions and the fact that it is less sensitive and has greater fault tolerance. Thus, ANNs are powerful supervised learning algorithms which have been widely applied in various fields such as in pattern recognition (Gencay 1998), data and image classification (Ganesan et al. 2010) as well as in other financial applications.

In this paper, a multilayer feedforward neural network is employed and implemented using Matlab. Such a model is applied because through a learning process that seeks to minimize the Normalized Mean Square Errors (NMSE) trading model, the ANNs predicted output is quite close to the actual close and thus the implemented trading strategies do not produce excessive losses not only in testing and validation periods, but also in an out-of-sample period. 
We follow Yao et al. (1999) and consider nine inputs $\left(\mathrm{C}_{\mathrm{t}}, \mathrm{C}_{\mathrm{t}-1}, \mathrm{MA}_{5}, \mathrm{MA}_{10}\right.$, $\mathrm{MA}_{50}, \mathrm{RSI}, \mathrm{M}, \% \mathrm{~K}$ and $\left.\% \mathrm{D}\right)$. The final output is an estimated value of $\hat{C}_{t+1}$. The three trading strategies are:

Strategy 1: if $\hat{C}_{t+1}>\hat{C}_{t}$, then buy else sell

Strategy 2: if $\hat{C}_{t+1}>C_{t}$, then buy else sell

Base Strategy: if $\hat{C}_{t}>C_{t}$ then buy else sell

Here, $C_{t}$ is the actual close at time $t$ and $\hat{C}_{t}$ is the prediction output obtained from the neural networks estimation process.

\section{Empirical Findings}

In this section, performances of the trading models, including the base strategy, are evaluated against that of the passive buy-and-hold strategy (Tables $2,3,4 \& 5)$.

Table 2. Trading Strategies Results on KLCI Returns from 2/1/2008 to $31 / 12 / 2012$

\begin{tabular}{|c|c|c|c|c|}
\hline \multicolumn{5}{|c|}{ Training Period: $2^{\text {nd }}$ January 2008 to $31^{\text {st }}$ December 2012 } \\
\hline Year & Buy-and-hold & Strategy 1 & Strategy 2 & Base Strategy \\
\hline $\mathbf{2 0 0 8}$ & $-39 \%$ & $-1 \%$ & $37 \%$ & $2 \%$ \\
\hline $\mathbf{2 0 0 9}$ & $38 \%$ & $6 \%$ & $54 \%$ & $13 \%$ \\
\hline $\mathbf{2 0 1 0}$ & $18 \%$ & $-1 \%$ & $6 \%$ & $26 \%$ \\
\hline $\mathbf{2 0 1 1}$ & $0 \%$ & $6 \%$ & $28 \%$ & $7 \%$ \\
\hline $\mathbf{2 0 1 2}$ & $12 \%$ & $10 \%$ & $19 \%$ & $-1 \%$ \\
\hline
\end{tabular}

Source: Authors' estimations.

Table 3. Trading Strategies Results on KLCI Returns from 2/1/2013 to $31 / 12 / 2013$

\begin{tabular}{|c|c|c|c|c|}
\hline \multicolumn{5}{|c|}{ Validation Period: $2^{\text {nd }}$ January 2013 to $31^{\text {st }}$ December 2013} \\
\hline Year & Buy-and-hold & Strategy 1 & Strategy 2 & Base Strategy \\
\hline $\mathbf{2 0 1 3}$ & $11 \%$ & $1 \%$ & $1 \%$ & $21 \%$ \\
\hline
\end{tabular}

Source: Authors' estimations.

Table 4. Trading Strategies Results on KLCI Returns from 2/1/2014 to $31 / 12 / 2014$

\begin{tabular}{|c|c|c|c|c|}
\hline \multicolumn{5}{|c|}{ Out-of-Sample Period: $2^{\text {nd }}$ January 2014 to $31^{\text {st }}$ December 2014} \\
\hline Year & Buy-and-hold & Strategy 1 & Strategy 2 & Base Strategy \\
\hline $\mathbf{2 0 1 4}$ & $-6 \%$ & $0 \%$ & $9 \%$ & $6 \%$ \\
\hline
\end{tabular}

Source: Authors' estimations. 
Vol. 2, No. 1 Phooi M'ng et al.: The Using Neural Networks to Enhance Technica...

Table 5. Trading Strategies Results on KLCI Returns from 2/1/2008 to $31 / 12 / 2014$

\begin{tabular}{|c|c|c|c|c|}
\hline \multicolumn{5}{|c|}{ Entire Test Period: $2^{\text {nd }}$ January 2008 to $31^{\text {st }}$ December 2014} \\
\hline & Buy-and-hold & Strategy $\mathbf{1}$ & Strategy 2 & Base Strategy \\
\hline $\mathbf{2 0 0 8} \mathbf{- 2 0 1 4}$ & $34 \%$ & $21 \%$ & $154 \%$ & $74 \%$ \\
\hline
\end{tabular}

Source: Authors' estimations.

The graph of KLCI and the predicted values for the out-of-sample period are illustrated in Figure 1.

Figure 1. Prediction Values of KLCI Daily Stock Price Index for Out-ofSample Period (02/01/2014 to 31/12/2014)

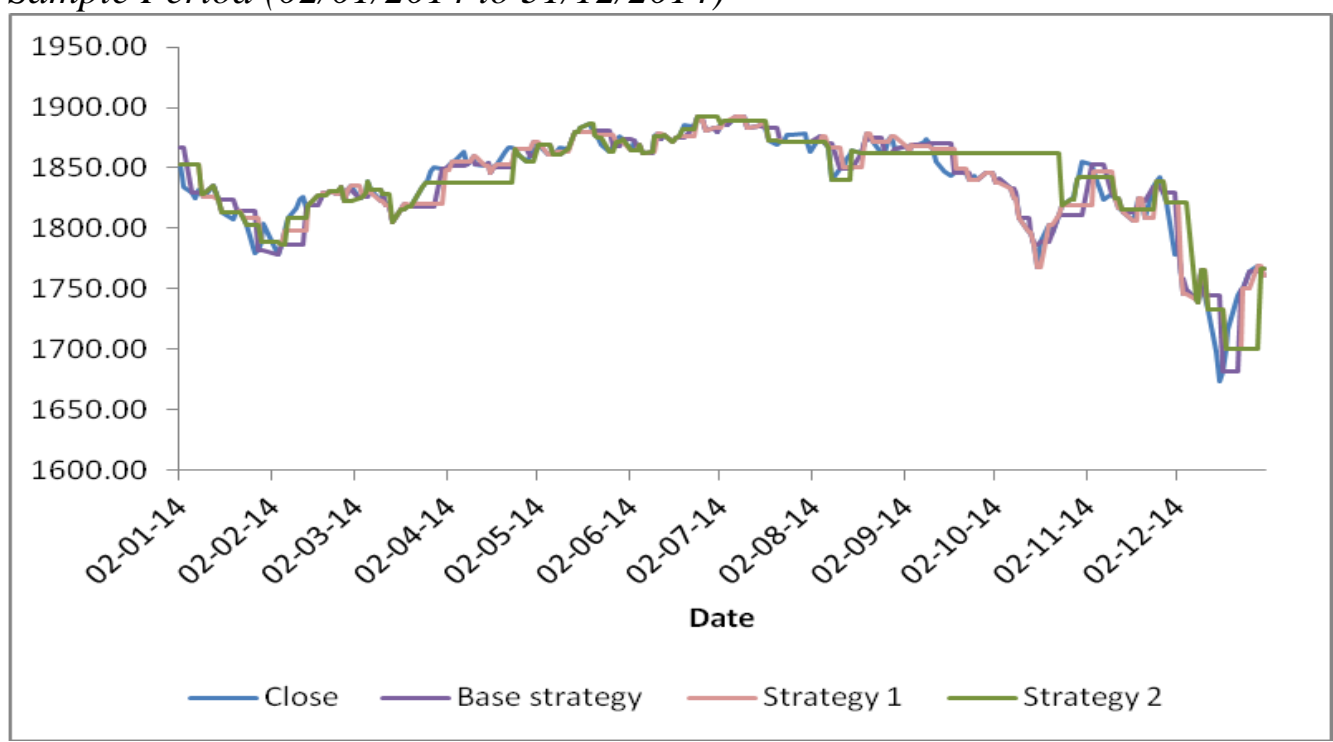

Source: Authors' estimations.

In summary, the results show that two out of the three trading rules using ANNs have performed better than the passive buy-and-hold strategy $(\mathrm{BH})$ over the entire period of seven years with Strategy 2 performing the best with a return of $154 \%$, while Base Strategy gives a return of $74 \%$. Strategy 1 gives a lower return $(21 \%)$ than the buy-and-hold strategy of $34 \%$.

\section{Conclusions}

Using KLCI for the period from 2008 to 2012 as a training period, 2013 for the validation period and 2014 as the out-of-sample period, this study assesses the efficacy of the nine technical trading indicators namely $\mathrm{C}_{\mathrm{t}}, \mathrm{C}_{\mathrm{t}-1}$, $\mathrm{MA}_{5}, \mathrm{MA}_{10}, \mathrm{MA}_{50}, \mathrm{RSI}, \mathrm{M}, \% \mathrm{~K}$ and $\% \mathrm{D}$. 


$\begin{array}{lcccc}\text { Period } & \text { Buy-and-hold } & \text { Strategy 1 } & \text { Strategy 2 } & \text { Base Strategy } \\ \text { Training } & 29 \% & 20 \% & 144 \% & 47 \% \\ \text { Validation } & 11 \% & 1 \% & 1 \% & 21 \% \\ \text { Out-of- Sample } & -6 \% & 0 \% & 9 \% & 6 \% \\ \text { Total } & 34 \% & 21 \% & 154 \% & 74 \% \\ \text { Annual Mean Return } & 4.86 \% & 3 \% & 22 \% & 10.57 \%\end{array}$

Strategy 2 and the Base Strategy outperform the passive buy-and-hold strategy with annual mean returns of $22 \%$ and $10.57 \%$ respectively, compared with the annual mean return of $4.86 \%$ if the investor had bought and held.

By and large, the results show that two out of three trading models are able to outperform the passive buy-and-hold strategy. Strategy 2 is by far the most robust. This is consistent with the studies conducted by Lukac et al. (1988), Brock et al. (1992) and Andrada-Felix et al. (2008) that the machine learning technical indicator strategies perform better than the simple buy-and-hold.

To conclude, overall, this paper demonstrates the efficacy of neural network enhanced technical indicators using KLCI, with Strategy 2 and the Base Strategy showing abnormal returns above the benchmark buy-and-hold. The study is limited to one market, a relatively short period of time and fixed technical indicators. Thus, it is worthwhile further exploring ANNs enhanced technical indicators for other stock and foreign exchange markets in future research. Against this backdrop, for researchers and academics, neural network enhanced technical indicators, as demonstrated in this piece of research, point to a new direction for science and the future of machine learning on time series.

\section{References}

Allen H, Taylor M (1990) Charts, noise and fundamentals in the London foreign exchange market. Economic Journal 100: 49-59.

Andrada-Felix J, Fernandex-Rodriquez F (2008) Improving moving average trading rules with boosting and statistical learning methods. Journal of Forecasting 27(5): 433-449.

Brock W, Lakonishok J, LeBaron B (1992) Simple technical trading rules and the stochastic properties of stock returns. Journal of Finance 47: 1731-1764.

Fama EF (1965) The behavior of stock market prices. Journal of Business 38: 34-105.

Fernandez-Rodriguez F, Gonzalez-Martel C, Sosvilla-Rivero S (2000) On the profitability of technical trading rules based on artificial neural networks: evidence from the Madrid stock market. Economics Letters 69: 89-94.

Fernandez-Perez A, Fernández Rodríguez F, Sosvilla Rivero S (2012) Genetic Algorithm for Arbitrage with More than Three Currencies. DEFI Working Paper No. 12-04. Asciacion Espanola de Economia y Finanzas Internacionales.

Ganesan N,Venkatesh K, Rama MA, Palani AM (2010) Application of neural networks in diagnosing cancer disease using demographic data. International Journal of Computer Applications 1(26): 76-85.

Gehrig T, Menkhoff L (2006) Extended evidence on the use of technical analysis in foreign exchange. International Journal of Finance and Economics 11: 327-338. 
Gencay R (1998) The predictability of security returns with simple trading rules. Journal of Empirical Finance 5: 347-359.

Gencay R, Stengos T (1998) Moving average rules, volume and the predictability of security returns with feedforward networks. Journal of Forecasting 17: 401-414.

Lee CI, Mathur I (1996) Trading rule profits in European currency spot cross-rates. Journal of Banking and Finance 20(5): 949-962.

Lukac L, Brorsen B, Irwin S (1988) A test of futures market disequilibrium using twelve different technical trading systems. Applied Economics 20: 623-639.

Masteika S, Rutkauskas AV (2012) Research on futures trend trading strategy based on short term chart pattern. Journal of Business Economics and Management 13(5): 915-930.

Neely C, Weller P, Ulrich J (2009) The adaptive markets hypothesis: evidence from the foreign exchange market. Journal of Financial and Quantitative Analysis 44: 467-488.

Olson D (2004) How trading rule profits in the currency markets declined over time? Journal of Banking and Finance 28: 85-105.

Park CH, Irwin SH (2009) A reality check on technical trading rule profits in the US futures markets. Journal of Futures Markets 30: 633-659.

Yao J, Chew L, Poh H (1999) Neural networks for technical analysis: a study on KLCI. International Journal of Theoretical and Applied Finance 2(2): 221-242.

Zhang GP (2003) Time series forecasting using a hybrid ARIMA and neural network model. Neurocomputing 50: 159-175. 